\title{
THE ETHICS OF COMMERCIAL PET CLONING
}

Shengyu Liu, University of the West, U.S.A. Peng Chan, California State University-Fullerton, U.S.A.

dx.doi.org/10.18374/JABE-20-3.1

\begin{abstract}
With the commercialization of cloning technologies, it is not surprising that the pet cloning business is gaining more traction. Owners generally want to keep their pet companions for as long as possible, but since they are unable to control the demise of their pets, the demand for cloning is on the rise. Cloning pets is becoming popular among people who want to "reclaim" their pets that have passed away. With cloning technology being commercialized, a key question is whether it will bring positive benefits or more ethical problems for society. This paper examines the ethical issues that commercial cloning enterprises face despite some benefits they may bring to society. It will also take a special look at the situation in China since many issues have emerged from there lately.
\end{abstract}

Keywords: Commercial cloning technology; Pet cloning; Ethics; China 